\title{
Investigation of Two Cover Stitch Machines in Terms of Process Times, Quality Levels and Their Expenses
}

\author{
Mehmet Kucuk \\ Textile Engineering Department, Engineering Faculty, \\ Ege University, 35100 Bornova, Izmir, Turkey \\ E-mail: mehmet.kucuk@ege.edu.tr
}

\begin{abstract}
In an ever-changing market environment, companies should continue developing their own businesses in accordance with the new technologies in order to increase their activities compared to their competitors. In this study, the processing of the twin needle cover stitch (406) in an automatic and nonautomatic machine, which are used extensively in most of the clothing products, were compared in terms of process times, quality and cost. As a result of these comparisons made, the time studies taken on the two systems showed that the process times were very close to each other. The difference was due to the repairing process which is handwork (not the machine) for the non-automatic machine. When the cover stitch processes of a basic t-shirt (a hemline and two sleeves) is taking into account, even though the sales price of the automatic machine is higher than the non-automatic one, the calculations showed that the total costs (considering machine sales prices and labor cost) of these two systems come up to 6187th tshirts (Figure A). For each t-shirt to be processed from this number, it was seen that the total cost of nonautomatic machine exceeded the automatic machine's cost.
\end{abstract}

Keywords: Automatic cover stitch, clothing industry, clothing quality, non-automatic cover stitch, productivity, the 4-point system

DOI: $10.7176 / \mathrm{JSTR} / 5-7-11$

\section{Introduction}

The effects of "Fast-Fashion" necessitated the low amount of orders, the short PLC effect, the necessity of meeting the demands of the customers in a short time, regardless of B2B or B2C. For all these reasons, clothing enterprises should maintain their activities in a fast way with high quality and as low costs as possible. In this direction, companies follow the constantly developing technology, make some motion and time study and carry out studies to determine the shortest time and the method for performing the required activity. Due to the labor intensive structure of this sector, various researches are carried out to determine the optimum limits in terms of time, labor, cost and quality by obtaining the necessary productivity increase in enterprises that need a large number of labor force and reducing the dependence on human power with the possible degree of automation (Kurumer, 2007).

Güner (2018) mentioned that for more than 160 years the clothing industry has been undergoing a process of change and transformation from hand sewing to automation and robotization.

The machines used in clothing production are highly developed today compared to past and many processes that require operator's hand work can be operated through various process apparatuses, computers and also automats. Developments in the field of clothing have been aimed at increasing the production speed as well as providing standardized and high quality. However, many operations still depend on the operator in the sector, even today. One of these processes is the cover stitch which is one of the most preferred sewing types.

Twin needle cover stitch (406) is a chain stitch type formed with 3 threads. The red colored yarns shown in Figure 1 are needles' and the yellows are looper's yarn. In the cover stitch, the needle and the looper yarns are connected to each other and complete this seam (Kurumer and Bozkurt, 1992). 


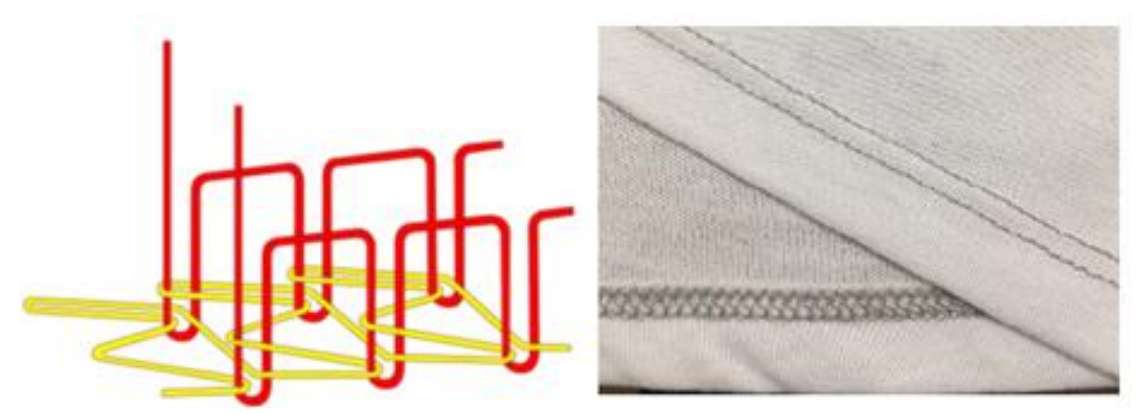

Figure 1. Schematic (left), front and rear (right) view of the twin needle cover stitch (406)

The twin needle cover stitch is one of the most commonly used multi-thread chain stitch types. It is usually used in the unprocessed edges of the products to clean the edges of the fabric as a closure stitch. According to the place of use, the stitching seams vary such as "Hemming" "Binding" and etc.

In this study, various investigations were made on the twin needle cover stitch. Process time, sewing quality and cost comparisons were carried out in the automatic and non-automatic twin needle cover stitch machines. The process times were obtained by making time study activities and sewing quality comparisons were performed by using 4-point system. In the cost comparisons, the machine prices, the labor cost per minute, the number of the products that require reparation due to quality standards.

The following studies can be given as the examples that have been carried out on comparison methods until today.

In a study named "An Investigation on Bathrobe Manufacturing Management" which was conducted by Duru Baykal and Tunç in 2011, the manufacturing processes of a selected bathrobe was researched. Time studies and process analysis were analysed and the standard times of the processes were calculated. Also the bottleneck points were determined. In 2015, Ala and İkiz have analyzed the fabric defects of terry fabrics. The number and the dimensions of the defects were recorded on the quality control papers. Detected defects were analyzed and scored according to different demerit point systems. In a study by Gürarda in 2015, the relation between the manufacturing processes and fabric properties were investigated and the ideal fabric was tried to find for a good handle and good garment appearance. In this study, 4-point system was used to determine the appropriate fabric concept.

\section{Material-Method}

\subsection{Material}

The material of this study consists of a t-shirt and the fabric of this t-shirt is $30 / 1,100 \%$ cotton, $140 \mathrm{gr} / \mathrm{m}^{2}$ weighted jersey fabric, and the twin needle cover stitch machines used in the sewing phase of a hemline and two sleeves to complete the production process. 2 different types of cover stitch machines were used for the comparison. In this study, Juki MF-7923-H23-B56-UT57-MC37/SC921/CP18 automatic cover stitch machine was compared with Juki MF-7923-U11-B56-UT57/SC921/CP18 non-automatic one. As the sewing thread, $100 \%$ polyester $150 \mathrm{dtex}^{*} 2$ was used in both machines during the production conducted by these two different types of machines.

\subsection{Method}

The processing time of the machines was measured with a stopwatch as the time measurement method. A REFA form was used for this step. The time measurement method with the stopwatch includes the following steps (Güner, 2015; Kurumer, 2007).

1- Detailed examination of the processes to ensure the usage of the most effective methods and movements.

2- Recording all available information relevant to process, the operator and the environmental conditions affecting the work.

3- Defining a complete description of the method and determining the process steps.

4- Grading the worker's processing speed according to the stopwatch user's own standard operating speed concept (rating).

5- Recording the time spent by the operator for each process step with the stopwatch.

6- Conversion of the observed times to "basic time" (Observed Time X Rating). 
7- Adding tolerances (relaxation allowance, unavoidable delays) to the basic time of the process, thus determining the "standard time" (Formula 1) (Güner, 2015).

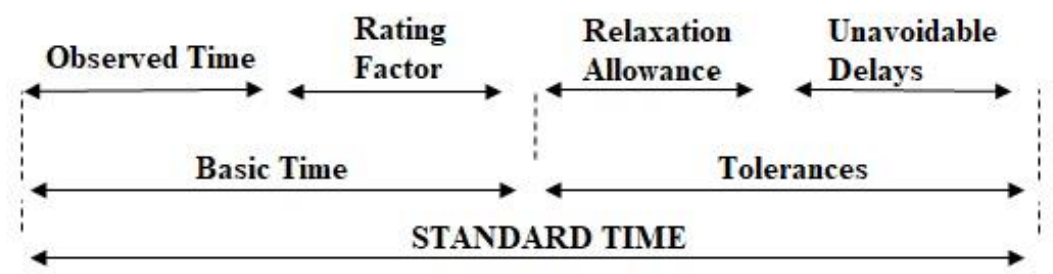

In this study, in addition to the basic time to be calculated for two different systems, the relaxation allowance will be included in the calculation as $4 \%$ and the unavoidable delays as $7 \%$. The relaxation allowance rate of $4 \%$ and the unavoidable delays rate of $7 \%$ are the actual tolerances used by the clothing company where the study is carried out. $20 \mathrm{t}$-shirts were prepared for time measurement. The hemline stitch of 10 of these $20 \mathrm{t}$-shirts were sewn with the automatic system, and rest of the t-shirts' hemline stitch was done with the non-automatic system. Similarly, the time measurement was made when using these machines in the sewing of sleeve hem stitches of the t-shirts.

After comparing the processing times of the two machines, the quality comparisons of the sewn products coming out of the machines were also made. Ala and Ikiz (2015) mentioned that, according to "The 4 Points System" which is one of the quality evaluation methods, was used in the comparison of sewing qualities. The 4 points system is one of the internationally accepted quality control applications. According to this method, all the types of the fault levels should be evaluated together. In this assessment, the values of each levels must be mathematically summed up and each class must be multiplied by their own coefficient of the faults (Table 1). After this process, the values of each classes are summed up and the final score of the system as a whole is obtained. The desired comparisons are realized based on the general scores obtained from the systems (https://tr.scribd.com/doc/94650324/4-Puan-Sistemi).

The amount of excess remaining after the edge stitches (cover stitch) of the fabric with the twin needle cover stitch was considered in the quality evaluations of the cover stitch of the products, showed in Figure 2 , which requires reparations. Because this assumes as the reason of the biggest quality problems for cover stitch process.

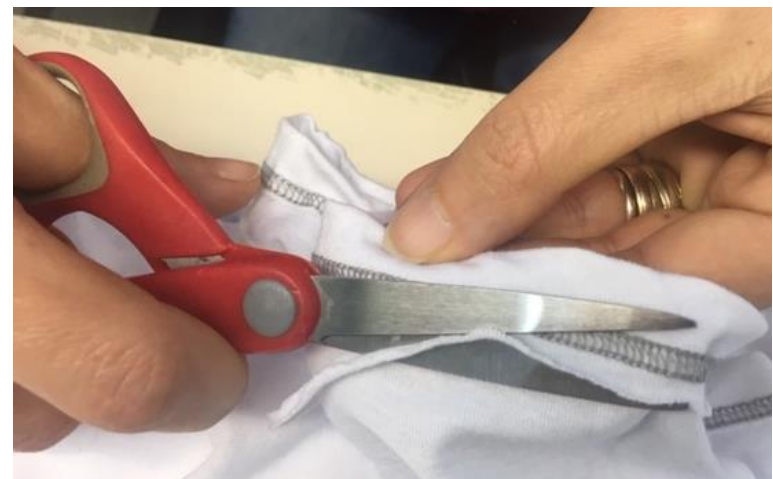

Figure 2. The reparation process of the cover stitch

According to the 4-point system, the levels and scores of the faults are as shown below.

Table 1. The types, weight coefficients and the codes of the faults

\begin{tabular}{|c|c|c|}
\hline The Types of the Faults $(\mathbf{m m})$ & Weight Coefficients* & Codes of the Faults \\
\hline $\mathrm{x} \leq 1$ & $\mathrm{n}=1$ point & White \\
\hline $1<\mathrm{x} \leq 2$ & $\mathrm{n}=2$ point & Green \\
\hline $2<\mathrm{x} \leq 4$ & $\mathrm{n}=3$ point & Yellow \\
\hline $4<\mathrm{x}$ & $\mathrm{n}=4$ point & Red \\
\hline
\end{tabular}


The t-shirt used in the comparison was size 38, and the twin needle cover stitch was used in the hemline and the sleeve hem stitches. The size of the hemline circumference of the size $38 \mathrm{t}$-shirt was $90 \mathrm{~cm}$ and the circumference of the sleeve hem was $36 \mathrm{~cm}$. According to this, the lengths and widths of the excess fabrics remaining in the inner part of the hemline and the sleeve hem were measured and evaluated with the 4-points system.

Finally, the sales prices of two different types of the twin needle cover stitch machines were evaluated. Consequently, a decision mechanism has been established to make the investment of the machine that gives better results considering the sales price of the two systems, the calculated standard times and labor minute costs.

\section{Findings}

The standard times obtained from the twin needle cover stitch processes of the hemlines as the results of the time measurements with the stopwatch are shown in Table 2.

Table 2. The standard times of the hemline cover stitches

\begin{tabular}{|c|c|c|c|c|c|c|c|c|c|c|c|c|}
\hline \multicolumn{13}{|c|}{ Hemline Records } \\
\hline & \multicolumn{6}{|c|}{ Non-Automatic System } & \multicolumn{6}{|c|}{ Automatic System } \\
\hline & \multicolumn{2}{|c|}{$\begin{array}{c}\text { Taking a piece } \\
\text { - putting under } \\
\text { the machine } \\
\end{array}$} & \multicolumn{2}{|c|}{ Sewing } & \multicolumn{2}{|c|}{$\begin{array}{c}\text { Putting the piece } \\
\text { away - taking } \\
\text { another one }\end{array}$} & \multicolumn{2}{|c|}{$\begin{array}{l}\text { Taking a piece - } \\
\text { putting under } \\
\text { the machine }\end{array}$} & \multicolumn{2}{|c|}{ Sewing } & \multicolumn{2}{|c|}{$\begin{array}{l}\text { Putting the piece } \\
\text { away - taking } \\
\text { another one }\end{array}$} \\
\hline & Sec & $\mathbf{R}$ & Sec & $\mathbf{R}$ & Sec & $\mathbf{R}$ & Sec & $\mathbf{R}$ & Sec & $\mathbf{R}$ & Sec & $\mathbf{R}$ \\
\hline Sample-1 & 5,35 & 110 & 9,48 & 90 & 2,5 & 100 & 5,15 & 100 & 10,01 & 100 & 1,2 & 110 \\
\hline Sample-2 & 5,98 & 110 & 8,16 & 100 & 2,5 & 100 & 4,06 & 105 & 10,08 & 100 & 1,04 & 90 \\
\hline Sample-3 & 6,13 & 100 & 8,33 & 100 & 2,5 & 90 & 5,1 & 100 & 10,5 & 95 & 1,52 & 90 \\
\hline Sample-4 & 7,08 & 95 & 8,61 & 105 & 2,1 & 100 & 5,09 & 90 & 10,2 & 100 & 1,5 & 100 \\
\hline Sample-5 & 7,71 & 90 & 8,3 & 105 & 1,8 & 100 & 5,4 & 100 & 10,5 & 100 & 1,1 & 95 \\
\hline Sample-6 & 7,11 & 90 & 8,93 & 100 & 2 & 90 & 4,8 & 105 & 10,4 & 90 & 1,3 & 105 \\
\hline Sample-7 & 6,54 & 100 & 9,19 & 100 & 2 & 100 & 5,36 & 100 & 10,7 & 100 & 1,2 & 105 \\
\hline Sample-8 & 6,6 & 100 & 9,15 & 100 & 1,7 & 105 & 5,2 & 100 & 10,4 & 90 & 1,4 & 100 \\
\hline Sample-9 & 6,7 & 100 & 9,2 & 95 & 1,9 & 100 & 4,8 & 105 & 9,6 & 105 & 1,1 & 105 \\
\hline Sample-10 & 6,58 & 100 & 10,6 & 85 & 2,2 & 100 & 4,7 & 105 & 10,48 & 95 & 1,1 & 95 \\
\hline Averages & 6,6 & 99,5 & 9,0 & 98,0 & 2,1 & 98,5 & 5,0 & 101,0 & 10,3 & 97,5 & 1,2 & 99,5 \\
\hline $\begin{array}{c}\text { Basic Time }= \\
\text { Avg Time x Avg Rating } \\
100\end{array}$ & \multicolumn{2}{|c|}{6,5} & \multicolumn{2}{|c|}{8,8} & \multicolumn{2}{|c|}{2,1} & & 0 & \multicolumn{2}{|c|}{10,0} & \multicolumn{2}{|c|}{1,2} \\
\hline Total Basic Time & \multicolumn{6}{|c|}{17,4} & \multicolumn{6}{|c|}{16,3} \\
\hline $\begin{array}{c}\text { Relaxation Allowance } \\
(\% 4)\end{array}$ & \multicolumn{6}{|c|}{0,70} & \multicolumn{6}{|c|}{0,65} \\
\hline $\begin{array}{c}\text { Unavoidable Delays } \\
(\% 7)\end{array}$ & \multicolumn{6}{|c|}{1,22} & \multicolumn{6}{|c|}{1,14} \\
\hline $\begin{array}{c}\text { STANDARD TIME } \\
(\mathrm{sec})\end{array}$ & \multicolumn{6}{|c|}{19,4} & \multicolumn{6}{|c|}{18,1} \\
\hline
\end{tabular}

When the standard times, obtained from the time measurement with the stopwatch of two different twin needle cover stitch machines, the time of hemline cover stitch with automatic system was calculated as $18.1 \mathrm{sec}$ and the time of hemline cover stitch with non-automatic was calculated as $19.4 \mathrm{sec}$. As a result of this data, the automatic system saves $1.3 \mathrm{sec}$. of the processing time of the unit product in hemline cover stitch process at the length of $90 \mathrm{~cm}$ for a size $38 \mathrm{t}$-shirt.

Similarly, the sleeves' cover stitch processes were also measured and the data obtained are indicated in Table 3 below. 
Table 3. The standard times of the sleeve hem cover stitches

\begin{tabular}{|c|c|c|c|c|c|c|c|c|c|c|c|c|c|c|c|c|}
\hline \multirow[t]{4}{*}{ Hemline Records } & \multicolumn{16}{|c|}{ Sleeve Hem Records } \\
\hline & \multicolumn{8}{|c|}{ Non-Automatic System } & \multicolumn{8}{|c|}{ Automatic System } \\
\hline & \multicolumn{2}{|c|}{$\begin{array}{c}\text { Taking a } \\
\text { piece - } \\
\text { putting } \\
\text { under the }\end{array}$} & \multicolumn{2}{|c|}{$\begin{array}{c}\text { Sewing } \\
\text { (Left One) }\end{array}$} & \multicolumn{2}{|c|}{$\begin{array}{c}\text { Sewing } \\
\text { (Right One) }\end{array}$} & \multicolumn{2}{|c|}{$\begin{array}{l}\text { Putting the piece } \\
\text { away - taking } \\
\text { another one }\end{array}$} & \multicolumn{2}{|c|}{$\begin{array}{c}\text { Taking a piece - } \\
\text { putting under } \\
\text { the machine }\end{array}$} & \multicolumn{2}{|c|}{$\begin{array}{c}\text { Sewing } \\
\text { (Left One) }\end{array}$} & \multicolumn{2}{|c|}{$\begin{array}{c}\text { Sewing } \\
\text { (Right One) }\end{array}$} & \multicolumn{2}{|c|}{$\begin{array}{l}\text { Putting the piece } \\
\text { away - taking } \\
\text { another one }\end{array}$} \\
\hline & Sec & $\mathbf{R}$ & Sec & $\mathbf{R}$ & Sec & $\mathbf{R}$ & $\mathrm{Sec}$ & $\mathbf{R}$ & Sec & $\mathbf{R}$ & Sec & $\mathbf{R}$ & Sec & $\mathbf{R}$ & Sec & $\mathbf{R}$ \\
\hline Sample-1 & 4,2 & 105 & 7,76 & 95 & 11,18 & 90 & 1 & 100 & 3,2 & 100 & 7,25 & 100 & 5,19 & 105 & 1,2 & 100 \\
\hline Sample-2 & 5,58 & 95 & 6,9 & 105 & 8,98 & 100 & 1 & 100 & 3,1 & 100 & 6,8 & 110 & 5,55 & 105 & 1 & 100 \\
\hline Sample-3 & 5,2 & 95 & 9,05 & 90 & 6,11 & 110 & 2 & 90 & 2,9 & 100 & 11,6 & 90 & 5,53 & 100 & 1,5 & 95 \\
\hline Sample-4 & 3,66 & 115 & 6,5 & 105 & 8,56 & 100 & 1,5 & 95 & 3,6 & 95 & 8,9 & 100 & 6,6 & 100 & 1 & 100 \\
\hline Sample-5 & 4,6 & 100 & 7,1 & 100 & 9,1 & 100 & 2 & 90 & 3,4 & 95 & 10 & 95 & 7,8 & 90 & 1,2 & 100 \\
\hline Sample-6 & 4,81 & 100 & 8 & 95 & 8,6 & 100 & 2 & 90 & 3,4 & 100 & 8,6 & 100 & 7,1 & 90 & 1 & 100 \\
\hline Sample-7 & 5 & 95 & 7,6 & 105 & 10,15 & 95 & 1 & 100 & 3 & 100 & 8,9 & 100 & 6,55 & 100 & 1 & 100 \\
\hline Sample-8 & 4,8 & 100 & 7,5 & 105 & 9,5 & 100 & 1 & 100 & 3,5 & 105 & 9 & 100 & 6,6 & 90 & 1,2 & 100 \\
\hline Sample-9 & 4,7 & 100 & 7,7 & 100 & 10,5 & 90 & 1 & 100 & 3 & 100 & 8,7 & 100 & 6,2 & 100 & 1,4 & 95 \\
\hline Sample-10 & 4,8 & 100 & 8 & 95 & 9 & 100 & 1 & 100 & 2,85 & 100 & 10,1 & 95 & 6,3 & 100 & 1 & 100 \\
\hline Averages & 4,7 & 100,5 & 7,6 & 99,5 & 9,2 & 98,5 & 1,4 & 96,5 & 3,2 & 99,5 & 9,0 & 99,0 & 6,3 & 98,0 & 1,2 & 99,0 \\
\hline $\begin{array}{c}\text { Basic Time }= \\
\text { Avg Time x Avg Rating } \\
100 \\
\end{array}$ & \multicolumn{2}{|c|}{4,8} & \multicolumn{2}{|c|}{7,6} & \multicolumn{2}{|c|}{9,0} & \multicolumn{2}{|c|}{1,3} & \multicolumn{2}{|c|}{3,2} & & & \multicolumn{2}{|c|}{6,2} & \multicolumn{2}{|c|}{1,1} \\
\hline Total Basic Time & \multicolumn{8}{|c|}{22,7} & \multicolumn{8}{|c|}{19,4} \\
\hline $\begin{array}{c}\text { Relaxation Allowance } \\
(\% 4)\end{array}$ & \multicolumn{8}{|c|}{0,91} & \multicolumn{8}{|c|}{0,78} \\
\hline $\begin{array}{c}\text { Unavoidable Delays } \\
(\% 7)\end{array}$ & \multicolumn{8}{|c|}{1,59} & \multicolumn{8}{|c|}{1,36} \\
\hline $\begin{array}{c}\text { STANDARD TIME } \\
(\mathrm{sec})\end{array}$ & \multicolumn{8}{|c|}{25,2} & \multicolumn{8}{|c|}{21,6} \\
\hline
\end{tabular}

When standard times of sleeve hem cover stitch processes were calculated, one can see the following results: 21.6 seconds were calculated for the standard time in the automatic system and 25.2 seconds for the non-automatic system. It shows that the automatic system used in sleeve hem at the length of $36 \mathrm{~cm}$ for a size $38 \mathrm{t}$-shirt, saves 3.6 seconds in manufacturing of one product.

Considering the differences between the standard times, it is possible to say that the automatic system is more advantageous. However, in the comparison of this two systems, it was considered that not only the standard times but also the manufacturing quality should also be checked and compared. For this purpose, manufacturing quality of these systems were evaluated with the 4-point system. In the quality control process conducted with the 4-points system, the excessive fabric amount in the inner part after folding the edges as a result of the cover stitch process has been detected. The related images are shown in the figure below (Figure 3).

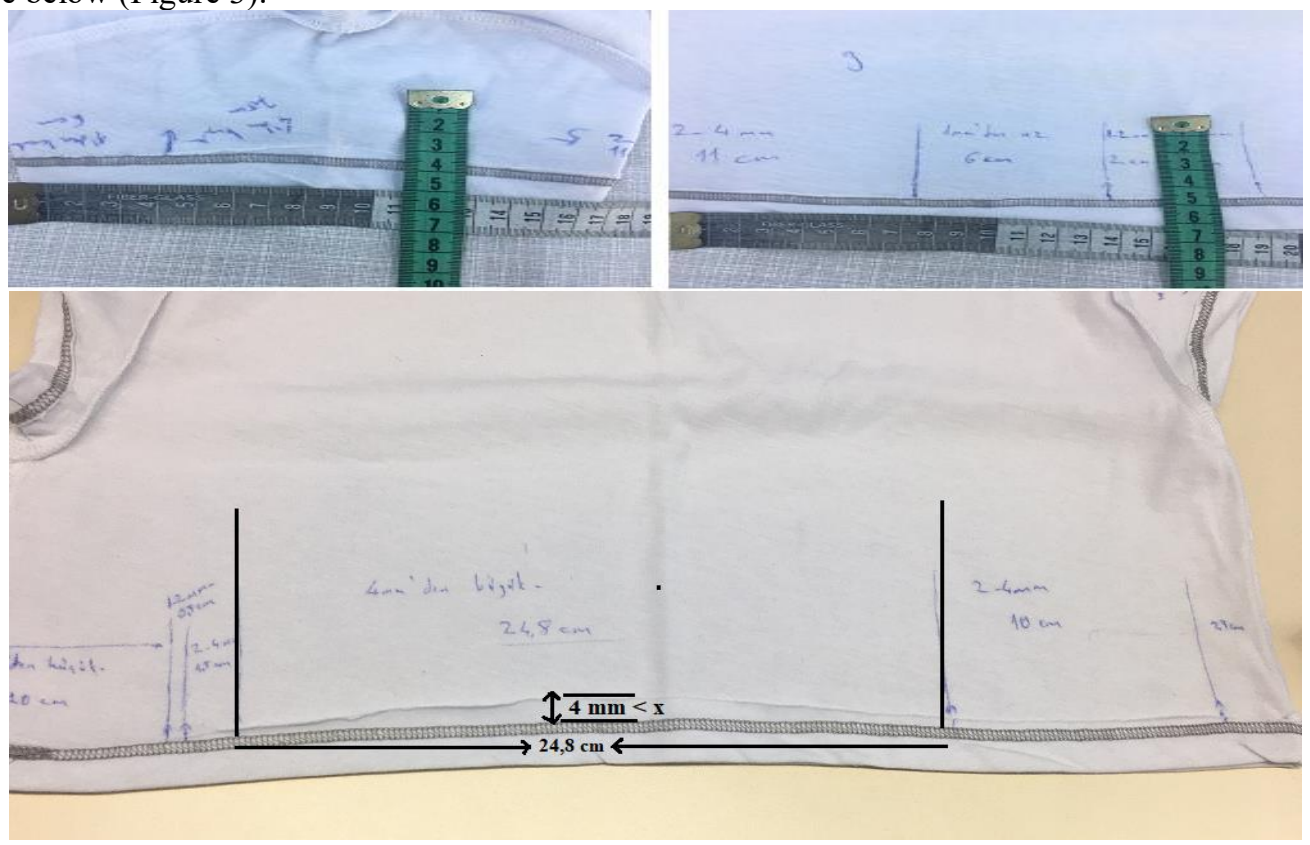

Figure 3. Quality-Control procedures of the t-shirts based on the 4-point system 
The tables obtained resulting from the quality control procedures performed according to the 4-point system are shown below. While Table 4 shows the data obtained from the hemline processes, Table 5 shows the data of the sleeve hems. It was found out that the excessive fabric (Figure 4), after the cover stitch process, remaining in the inner side should be less than $2 \mathrm{~mm}$ based on the interviews with various professional exporting companies in knitted garments. If a t-shirt contains more than $2 \mathrm{~mm}$ of excess fabric, it becomes necessary to repair this process (cutting the excess fabric with an additional process).

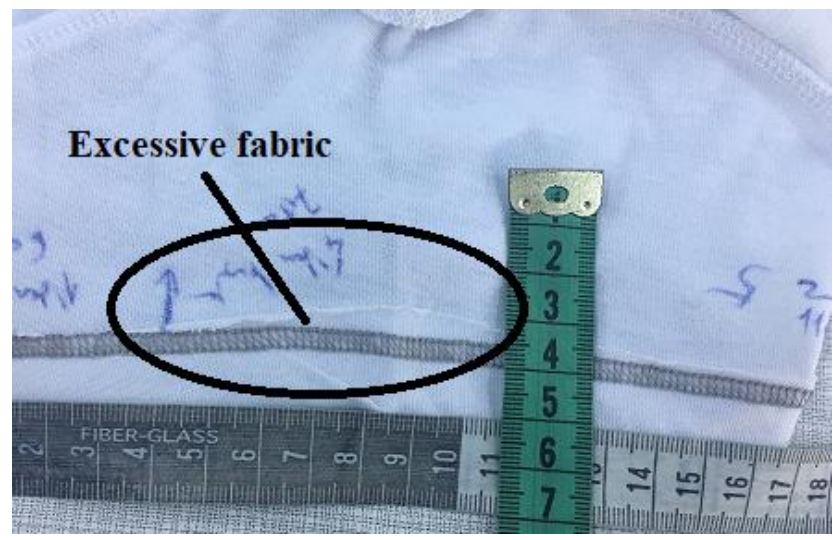

Figure 4. The detection of the excessive fabrics

Table 4. Quality-Control results of the hemline cover stitch

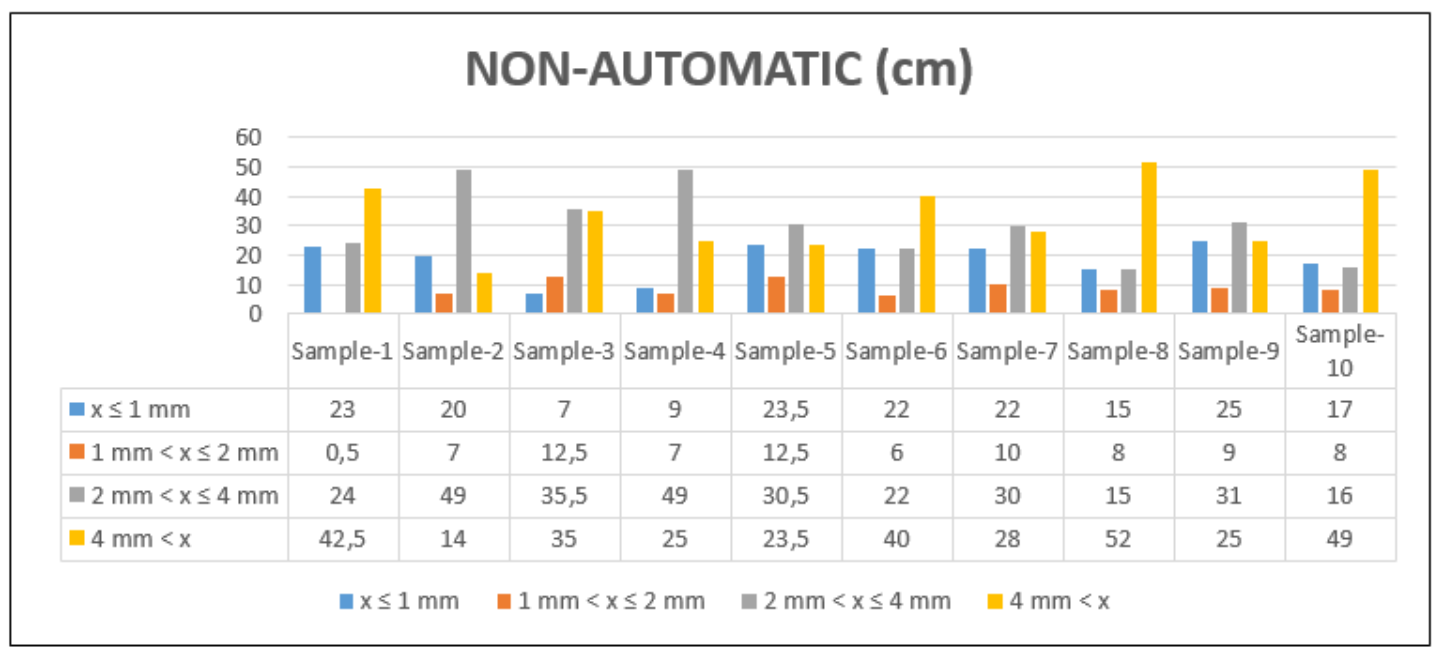

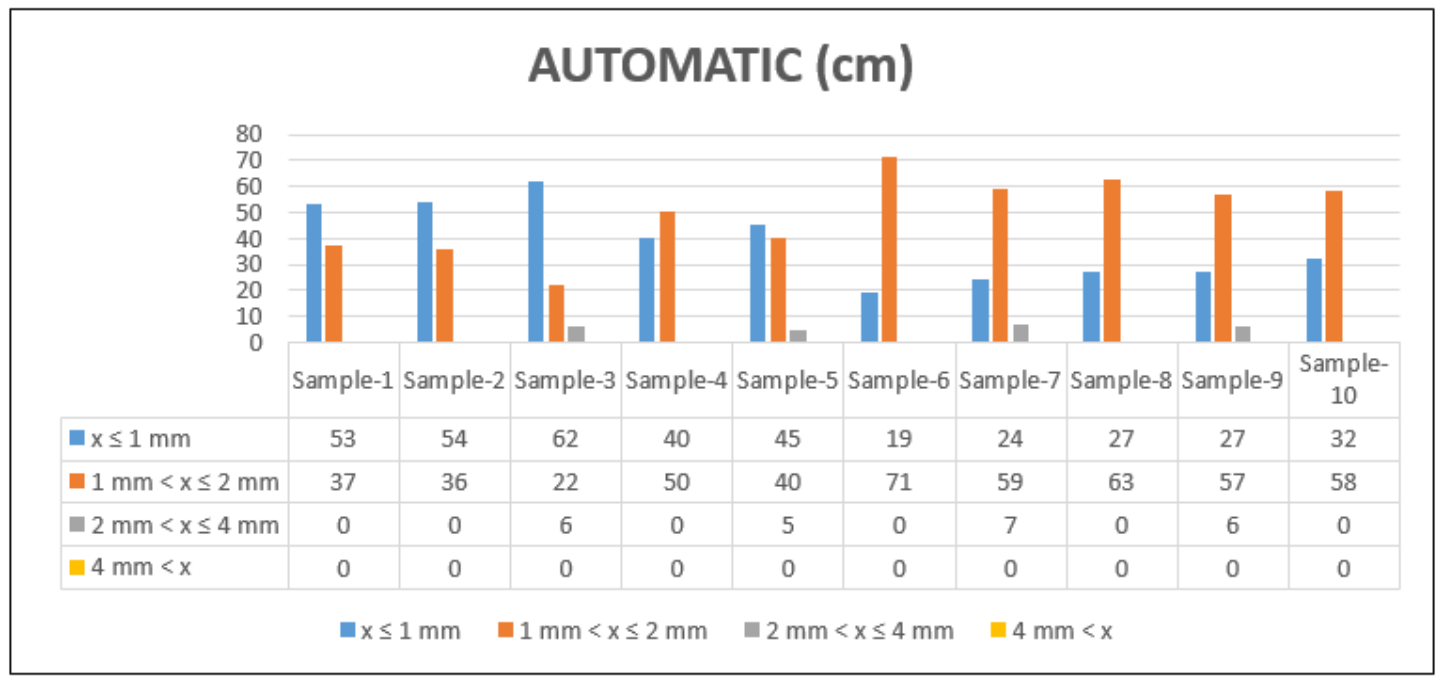


(Table 4. Quality-Control results of the hemline cover stitch)

\begin{tabular}{|c|c|c|c|}
\hline \multicolumn{2}{|c|}{ NON-AUTOMATIC (cm) } & \multicolumn{2}{|c|}{ AUTOMATIC (cm) } \\
\hline \multicolumn{2}{|c|}{ TOTAL DEVIATION (10 Samples) (cm) } & \multicolumn{2}{|c|}{ TOTAL DEVIATION (10 Samples) (cm) } \\
\hline $\mathrm{x} \leq 1 \mathrm{~mm}$ & 146,5 & $\mathrm{x} \leq 1 \mathrm{~mm}$ & 332,0 \\
\hline $1 \mathrm{~mm}<\mathrm{x} \leq 2 \mathrm{~mm}$ & 62,5 & $1 \mathrm{~mm}<\mathrm{x} \leq 2 \mathrm{~mm}$ & 371,0 \\
\hline $2 \mathrm{~mm}<\mathrm{x} \leq 4 \mathrm{~mm}$ & 257,0 & $2 \mathrm{~mm}<\mathrm{x} \leq 4 \mathrm{~mm}$ & 17,0 \\
\hline $4 \mathrm{~mm}<\mathrm{x}$ & 254,0 & $4 \mathrm{~mm}<\mathrm{x}$ & 0,0 \\
\hline \multicolumn{2}{|c|}{ WEIGHTED DEVIATION (n X Total) } & \multicolumn{2}{|c|}{ WEIGHTED DEVIATION (n X Total) } \\
\hline $\mathrm{x} \leq 1 \mathrm{~mm}(\mathrm{n} \times 1 *)$ & 146,5 & $\mathrm{x} \leq 1 \mathrm{~mm}\left(\mathrm{n} \times 1^{*}\right)$ & 332,0 \\
\hline $1 \mathrm{~mm}<\mathrm{x} \leq 2 \mathrm{~mm}\left(\mathrm{n} \times 2^{*}\right)$ & 125,0 & $1 \mathrm{~mm}<\mathrm{x} \leq 2 \mathrm{~mm}\left(\mathrm{n} \times 2^{*}\right)$ & 742,0 \\
\hline $2 \mathrm{~mm}<\mathrm{x} \leq 4 \mathrm{~mm}\left(\mathrm{n} \times 3^{*}\right)$ & 771,0 & $2 \mathrm{~mm}<\mathrm{x} \leq 4 \mathrm{~mm}\left(\mathrm{n} \mathrm{x} 3^{*}\right)$ & 51,0 \\
\hline $4 \mathrm{~mm}<\mathrm{x}\left(\mathrm{n} \mathrm{x} 4^{*}\right)$ & 1016,0 & $4 \mathrm{~mm}<\mathrm{x}\left(\mathrm{n} \times 4^{*}\right)$ & 0,0 \\
\hline TOTAL & 2058,5 & TOTAL & 1125,0 \\
\hline
\end{tabular}

The results obtained from the quality control processes within the 4-point system are classified in Table 4. According to the system, after the total deviations are calculated, the amount of the deviation from the desired level is controlled and leveled, then the weight coefficient is assigned to each level. After that the determined deviations is multiplied with the weight coefficients and the amount of total quality deviation of a product is calculated. Resulting from the calculations, the quality score of the t-shirts sewn with the automatic system is 1125 , while the score of the t-shirts obtained through the non-automatic system is calculated as 2058,5 .

Considering the interviews with the managers who are responsible in exporting companies' qualitycontrol departments, it was found out that the threshold quality level of cover stitch processes corresponds to a fabric excess (after folding) of $2 \mathrm{~mm}$. Therefore, if the fabric excess is considered to be $2 \mathrm{~mm}$ along the end of the hem, the deviation limit value of poor quality is equal to 1800 which is calculated and shown in the formula 2 below, according to the 4-point system. If this score is just more than 1800, it means the $\mathrm{t}$-shirts are not good enough and need reparations. According to this, the $\mathrm{t}$-shirts sewn with the automatic system are defined as qualified with 1125 points and the t-shirts sewn with a non-automatic system are considered as poor quality with 2058,5 points.

The Threshold Score = Tshirt Quantity x Seam Length $\mathrm{x}$ Threshold Quality Level

The Threshold Score $=10 \times 90 \times 2$

The Threshold Score $=1800$

Similarly, the following table and ratings are obtained considering the sewing process of the sleeve hem cover stitch process.

Table 5. Quality-Control results of the sleeve hem cover stitch

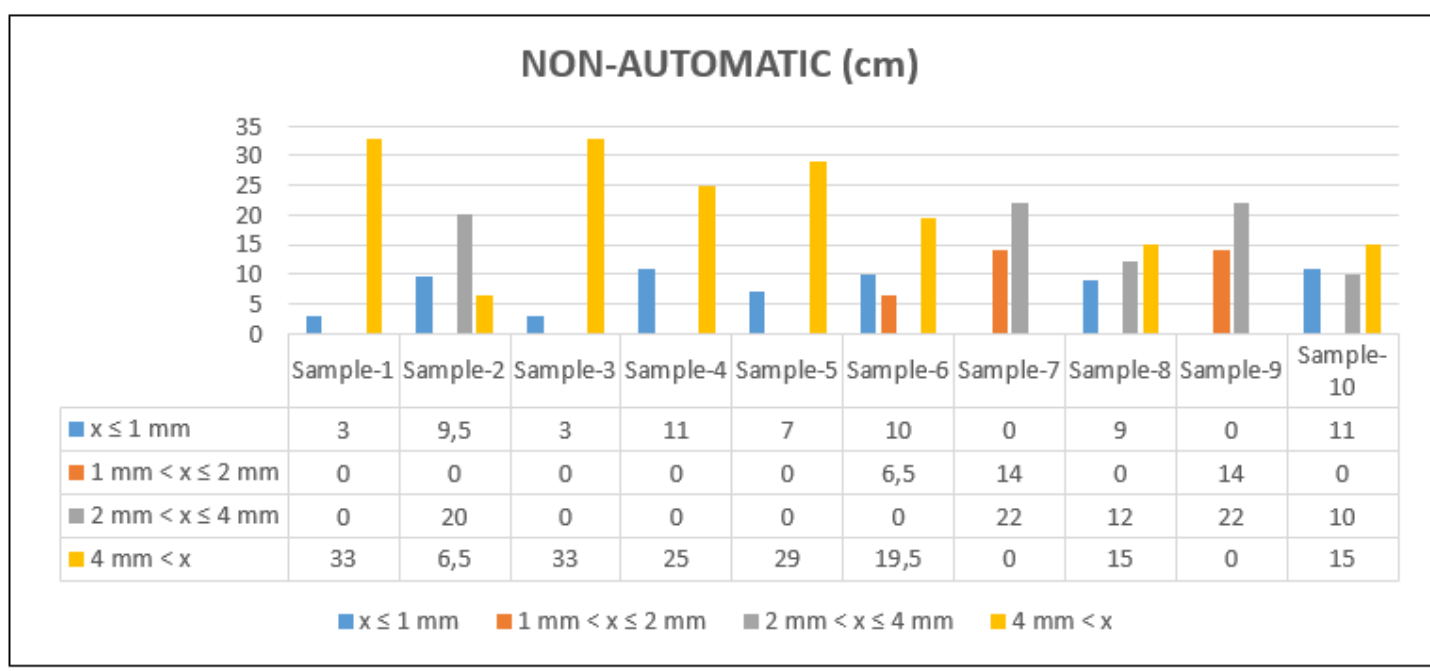




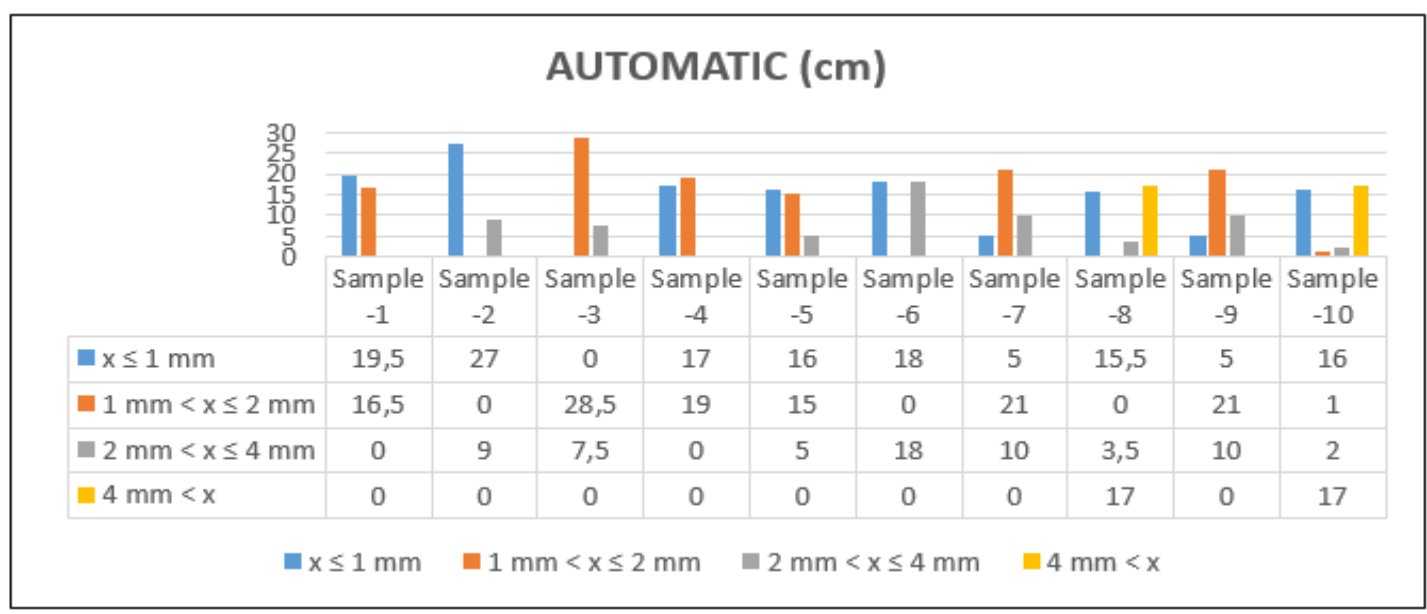

(Table 5. Quality-Control results of the sleeve hem cover stitch)

\begin{tabular}{|c|c|c|c|}
\hline \multirow{2}{*}{\multicolumn{2}{|c|}{$\begin{array}{c}\text { NON-AUTOMATIC }(\mathrm{cm}) \\
\text { TOTAL DEVIATION (10 Samples) }(\mathrm{cm})\end{array}$}} & \multicolumn{2}{|l|}{ AUTOMATIC $(\mathrm{cm})$} \\
\hline & & \multicolumn{2}{|c|}{ TOTAL DEVIATION (10 Samples) (cm) } \\
\hline $\mathrm{x} \leq 1 \mathrm{~mm}$ & 54,50 & $\mathrm{x} \leq 1 \mathrm{~mm}$ & 118,50 \\
\hline $1 \mathrm{~mm}<\mathrm{x} \leq 2 \mathrm{~mm}$ & 20,50 & $1 \mathrm{~mm}<\mathrm{x} \leq 2 \mathrm{~mm}$ & 101,00 \\
\hline $2 \mathrm{~mm}<\mathrm{x} \leq 4 \mathrm{~mm}$ & 52,00 & $2 \mathrm{~mm}<\mathrm{x} \leq 4 \mathrm{~mm}$ & 51,50 \\
\hline $4 \mathrm{~mm}<\mathrm{x}$ & 161,00 & $4 \mathrm{~mm}<\mathrm{x}$ & 17,00 \\
\hline \multicolumn{2}{|c|}{ WEIGHTED DEVIATION (n X Total) } & \multicolumn{2}{|c|}{ WEIGHTED DEVIATION (n X Total) } \\
\hline $\mathrm{x} \leq 1 \mathrm{~mm}\left(\mathrm{n} \times 1^{*}\right)$ & 54,5 & $\mathrm{x} \leq 1 \mathrm{~mm}\left(\mathrm{n} \times 1^{*}\right)$ & 118,5 \\
\hline $1 \mathrm{~mm}<\mathrm{x} \leq 2 \mathrm{~mm}\left(\mathrm{n} \times 2^{*}\right)$ & 41,0 & $1 \mathrm{~mm}<\mathrm{x} \leq 2 \mathrm{~mm}\left(\mathrm{n} \times 2^{*}\right)$ & 202,0 \\
\hline $2 \mathrm{~mm}<\mathrm{x} \leq 4 \mathrm{~mm}\left(\mathrm{n} \times 3^{*}\right)$ & 156,0 & $2 \mathrm{~mm}<\mathrm{x} \leq 4 \mathrm{~mm}\left(\mathrm{n} \times 3^{*}\right)$ & 154,5 \\
\hline $4 \mathrm{~mm}<\mathrm{x}\left(\mathrm{n} \times 4^{*}\right)$ & 644,0 & $4 \mathrm{~mm}<\mathrm{x}\left(\mathrm{n} \times 4^{*}\right)$ & 68,0 \\
\hline TOTAL & 895,5 & TOTAL & 543,0 \\
\hline
\end{tabular}

Similar to the hemline evaluations, the quality scores of the sleeve hem cover stitch process were calculated depending on these two sewing systems. According to this, the total quality score obtained from the automatic system was 543, while the score obtained from the non-automatic system was calculated as 895,5 . Assuming that the excess of fabric remaining as a result of the cover stitch process along the entire sleeves' circumference is at the limit value of $2 \mathrm{~mm}$, the acceptable total value (threshold quality level) is calculated as 720 which is shown below (Formula 2). Taking this value into account, the cover stitch processes with automatic system is described as good quality and the non-automatic system is considered to be of under the threshold level.

The Threshold Score = Tshirt Quantity $\mathrm{x}$ Seam Length $\mathrm{x}$ Threshold Quality Level The Threshold Score $=10 \times 36 \times 2$

The Threshold Score $=720$

In the case that the remaining fabric excesses after the cover stitch process are more than the customer tolerances (for instance $2 \mathrm{~mm}$ like in this study), the quality-control operator performs a reparation processes at the inner side of the cover stitch in order to eliminate this problem. This is realized by the quality-control operator by cutting the remaining excesses with the help of a scissors (Figure 3).

Within the scope of the study, the time measurement of the reparation process, which was carried out in order to eliminate the poor quality caused by the cover stitch process conducted for both the hemline and sleeve hem, was realized and the standard time was calculated (Table 6). 
Table 6. The standard times of the reparation of poor quality samples

\begin{tabular}{|c|c|c|c|c|c|c|c|c|c|c|c|c|}
\hline & \multicolumn{6}{|c|}{ Hemline Regulation } & \multicolumn{6}{|c|}{ Sleeve Hem Regulation } \\
\hline & \multicolumn{2}{|c|}{$\begin{array}{l}\text { Taking (T- } \\
\text { shirt ve } \\
\text { Scissors) }\end{array}$} & \multicolumn{2}{|c|}{ Cutting } & \multicolumn{2}{|c|}{$\begin{array}{l}\text { Putting the } \\
\text { piece away - } \\
\text { taking } \\
\text { another one }\end{array}$} & \multicolumn{2}{|c|}{$\begin{array}{c}\text { Taking (T- } \\
\text { shirt ve } \\
\text { Scissors) }\end{array}$} & \multicolumn{2}{|c|}{ Cutting } & \multicolumn{2}{|c|}{$\begin{array}{l}\text { Putting the } \\
\text { piece away - } \\
\text { taking } \\
\text { another one }\end{array}$} \\
\hline & $\mathrm{Sec}$ & $\mathbf{R}$ & Sec & $\mathbf{R}$ & Sec & $\mathbf{R}$ & Sec & $\mathbf{R}$ & Sec & $\mathbf{R}$ & Sec & $\mathbf{R}$ \\
\hline Sample-1 & 5,93 & 105 & 41,48 & 85 & 1,3 & 100 & 4,65 & 100 & 35 & 100 & 2 & 100 \\
\hline Sample-2 & 7,71 & 95 & 58,02 & 90 & 1,5 & 95 & 4,32 & 105 & 38,5 & 90 & 2,1 & 90 \\
\hline Sample-3 & 8,56 & 90 & 48,65 & 90 & 1,5 & 90 & 5,14 & 90 & 37 & 95 & 2,6 & 90 \\
\hline Sample-4 & 11,21 & 80 & 55,82 & 85 & 1 & 100 & 5,15 & 90 & 34,8 & 105 & 2,4 & 90 \\
\hline Sample-5 & 9,06 & 85 & 58,33 & 85 & 2 & 95 & 5 & 90 & 40 & 90 & 2 & 100 \\
\hline Sample-6 & 8,68 & 90 & 56,8 & 80 & 1,6 & 90 & 3,5 & 110 & 41,1 & 90 & 2 & 100 \\
\hline Sample-7 & 10,4 & 85 & 52,02 & 85 & 1,5 & 100 & 5,1 & 90 & 39,4 & 95 & 2,5 & 95 \\
\hline Sample-8 & 9,58 & 90 & 65 & 80 & 1,4 & 100 & 5 & 90 & 37,4 & 95 & 2 & 100 \\
\hline Sample-9 & 10,01 & 90 & 60 & 80 & 1,5 & 100 & 5,2 & 90 & 40,2 & 90 & 2,1 & 100 \\
\hline Sample-10 & 10,1 & 90 & 61 & 80 & 1,5 & 100 & 4,8 & 95 & 39 & 95 & 2,5 & 100 \\
\hline Averages & 9,1 & 90,0 & 55,7 & 84,0 & 1,5 & 97,0 & 4,8 & 95,0 & 38,2 & 94,5 & 2,2 & 96,5 \\
\hline $\begin{array}{c}\text { Basic Time }= \\
\text { Avg Time x Avg Rating } \\
100\end{array}$ & \multicolumn{2}{|c|}{8,2} & \multicolumn{2}{|c|}{46,8} & \multicolumn{2}{|c|}{1,4} & \multicolumn{2}{|c|}{4,5} & \multicolumn{2}{|c|}{36,1} & \multicolumn{2}{|c|}{2,1} \\
\hline Total Basic Time & \multicolumn{6}{|c|}{56,4} & \multicolumn{6}{|c|}{42,8} \\
\hline $\begin{array}{c}\text { Relaxation Allowance } \\
(\% 4)\end{array}$ & \multicolumn{6}{|c|}{2,26} & \multicolumn{6}{|c|}{1,71} \\
\hline $\begin{array}{c}\text { Unavoidable Delays } \\
(\% 7)\end{array}$ & \multicolumn{6}{|c|}{3,95} & \multicolumn{6}{|c|}{3,00} \\
\hline $\begin{array}{c}\text { STANDARD TIME } \\
(\mathrm{sec})\end{array}$ & \multicolumn{6}{|c|}{62,61} & \multicolumn{6}{|c|}{47,51} \\
\hline
\end{tabular}

The standard times obtained based on the reparation processes of the hemline and the sleeve hem cover stitch processes are shown in the table above (Table 6). According to the calculations, it has been determined that only the reparation time for the hemline was $62,61 \mathrm{sec}$, where the time spent on the reparation process for the sleeve hem was $47,51 \mathrm{sec}$. The reparation processing times should be included in the daily production target calculations within the production planning.

With the help of time measurements conducted for automatic and non-automatic systems, the standard time differences between the systems were calculated as follows on a product basis (Table 7).

Table 7. The standard time comparison of automatic and non-automatic systems

\begin{tabular}{|c|c|c|c|c|}
\hline & \multicolumn{2}{|c|}{ Non-Automatic System } & \multicolumn{2}{|c|}{ Automatic System } \\
\hline & $\begin{array}{c}\text { Sleeve hem } \\
\text { standard time } \\
\text { (sec) }\end{array}$ & $\begin{array}{c}\text { Hemline } \\
\text { standard time } \\
\text { (sec) }\end{array}$ & $\begin{array}{c}\text { Sleeve hem } \\
\text { standard time } \\
\text { (sec) }\end{array}$ & $\begin{array}{c}\text { Hemline } \\
\text { standard time } \\
\text { (sec) }\end{array}$ \\
\hline Standard Times & 25,2 & 19,4 & 21,6 & 18,1 \\
\hline Reparation Times & $+47,51$ & $+62,61$ & $\underline{0}$ & $\underline{0}$ \\
\hline TOTAL & $\underline{72,71}$ & 82,01 & 21,6 & $\underline{18,1}$ \\
\hline $\begin{array}{c}\text { Sum of } 2 \text { sleeves } 1 \\
\text { hemline standard } \\
\text { times on product } \\
\text { basis (sec) }\end{array}$ & \multicolumn{2}{|c|}{$\begin{array}{c}(72,71 \times 2)+(82,01)= \\
\underline{227,43}\end{array}$} & \multicolumn{2}{|c|}{$\begin{array}{c}(21,6 \times 2)+(18,1)= \\
\underline{61,3}\end{array}$} \\
\hline
\end{tabular}

Table 7 shows that the total time spent in the sleeve hem cover stitching with non-automatic system including the reparation process was $72,71 \mathrm{sec}$, while the processing time was calculated as $82,01 \mathrm{sec}$ for the hemline cover stitch seam. Total process time conducted with the automatic system was calculated 
as $21.6 \mathrm{sec}$ for sleeve hem and $18.1 \mathrm{sec}$ for hemline. On one product basis (considering that two sleeve hems and one hemline cover stitch processes), it was determined that the total standard time was 227,43 $\mathrm{sec}$ in the non-automatic system and while it was $61,3 \mathrm{sec}$ in the automatic system. These standard times were utilized in accordance with the investment decisions of the automatic and non-automatic systems. The prices of the machines with non-automatic and automatic systems have been determined, based on the interviews conducted with the manufacturers and distributors for March, 2019. Accordingly, the sales price of the non-automatic two needle cover stitch system (MF-7923-U11-B56-UT57 / SC921 / CP18) was 6.272 USD (incl. VAT), while the sales price of the automatic two needle cover stitch system (MF7923-H23-B56-UT57-MC37 / SC921 / CP18) was 7.128 USD (incl. VAT).

The standard times, the quality levels, the sales prices of both systems and the reparation process time spent for the non-automatic system were obtained. In addition, the operator who use these systems minute cost to the company was also calculated. For the calculation of this, the monthly salary of relevant operator and the working hours of the operators were obtained from the company. Operator receives monthly minimum wage (488 \$ which is the gross salary) and also the company works 8 hours a day/ 5 days a week. According to this, operator works 9600 minutes in a month. Considering that operator receives minimum wage each month, the minute cost of the operator can be calculated as follows.

$$
\begin{aligned}
& \text { Operator (labor) Minute Cost }=\frac{\text { Monthly Wage }}{\text { Monthly Working Time (dk) }} \\
& \text { Operator (labor) Minute Cost }=\frac{488}{9600}=0,051 \$ / \mathrm{min}
\end{aligned}
$$

According to the Formula 3, the minute cost of the operator is calculated as $0,051 \$ / \mathrm{min}$.

Table 8. 1 Operator (labor) cost of the t-shirt

\begin{tabular}{|c|c|c|}
\hline $\begin{array}{c}\text { Sum of 2 sleeves 1 hemline } \\
\text { standard times on product basis } \\
(\mathbf{s e c})\end{array}$ & $\underline{\mathbf{2 2 7 , 4 3}}$ & Automatic System \\
\hline $\begin{array}{c}\text { Operator cost of a t-shirt } \\
\text { (\$) }\end{array}$ & $\underline{\text { Standard Time x Operator minute cost }}$ \\
\hline $\begin{array}{c}\text { Operator cost of a t-shirt } \\
\text { (\$) }\end{array}$ & $\frac{227,43 \times 0,051}{60}=\mathbf{0 , 1 9 3}$ & $\frac{61,3 \times 0,051}{60}=\mathbf{0 , 0 5 2}$ \\
\hline
\end{tabular}

According to Table 8, Figure 5 was formed by considering the sales price of the systems (machines), the reparation process times of the products due to poor quality and the operator minute cost. The formula 4 was used when creating this graph (Figure 5).

Total Expense $=$ Machine Sales Price $+($ Number of Sewed Product $x$ Labor Cost of a tshirt $)$

Accordingly, the investment and the utilization costs of the two systems over time were examined. The sales prices of the systems are marked in Figure 5 which is formed by considering the investment and the usage costs of the systems. Following these points, the labor costs of the systems for each $\mathrm{t}$-shirt which is given in Table 8 are added to the sales prices. Thus, the junction point of these two systems were calculated at the 6.187 th t-shirt, while the total expense of investment and labor costs for these two systems was calculated as 7.445,61 \$. For each t-shirt produced over this number, the total expenses of the non-automatic system will exceed the total expenses of the automatic system. 


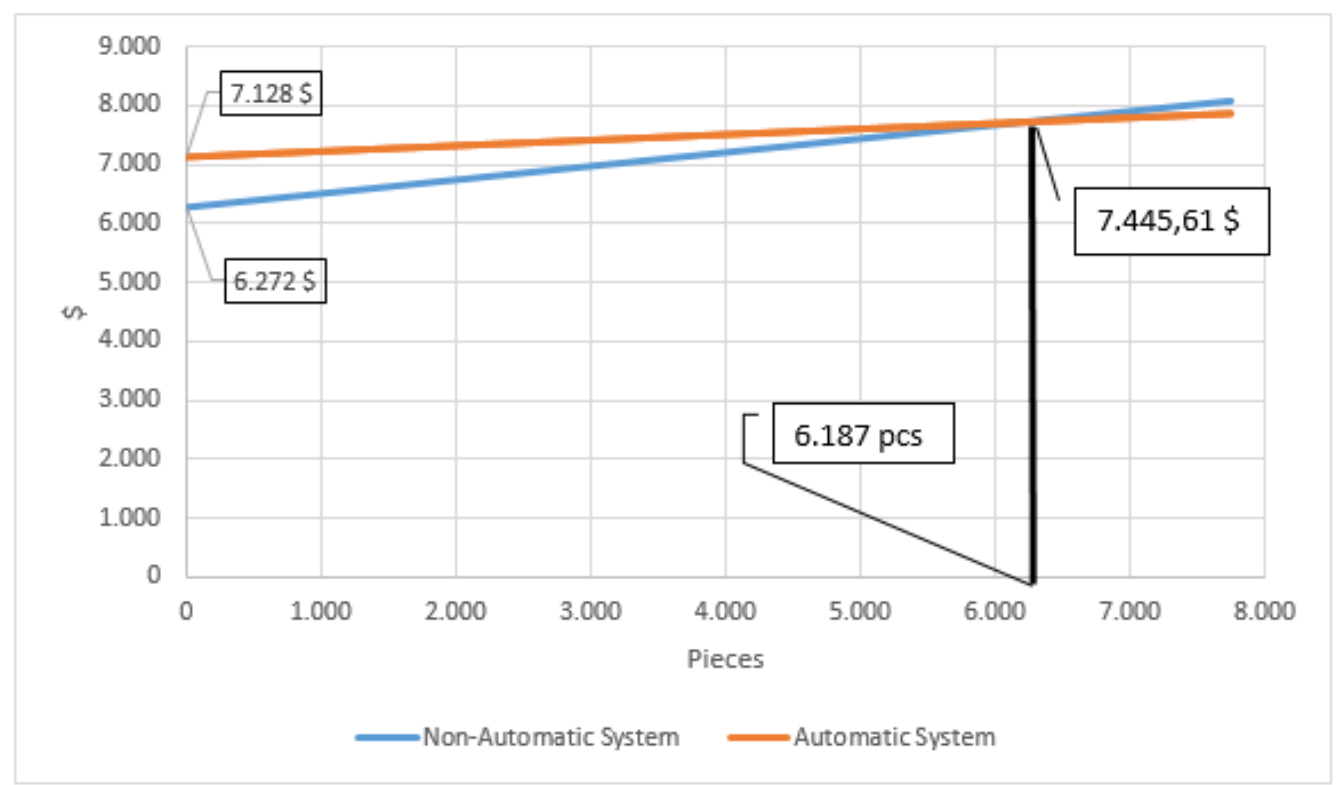

Figure 5. The break-even analysis of the systems

\section{Conclusion and Evaluation}

In today's challenging competitive environment, businesses have to undertake a number of technical preliminary investigations to outperform their competitors. Within the scope of these investigations, they have to consider the criteria that will be effective in the investment decisions. For a company operating in the clothing industry, one of these important criteria is the choice of machines to be used in production. Within the scope of this study, two different twin needle cover stitch machines alternatives, which are frequently used in the clothing companies, are discussed.

Two twin needle cover stitch machines which are automatic and non-automatic systems were examined as the different investment decisions. In order to make a systematic comparison and highlight the advantageous and disadvantaged aspects of the systems, the time measurement values of the processes conducted in two systems, quality evaluations of the sewn products through the 4-point system, the sales prices of the systems and labor costs were analyzed. It was found that the automatic system has higher investment cost and shorter process standard time, where the non-automatic system has a lower investment cost and longer standard time features. The reason that the non-automatic system requires longer time is due to the fact that the operators need to perform an additional reparation process. Therefore, the time spent by the operators per each product and accordingly the labor costs in the nonautomatic system are higher than the automatic system. From this point of view, the number of products need to be produced has been calculated where the costs of the two systems (the sum of systems' sales prices and the labor cost required for the product) are equalized. According to this, the total costs of the two systems are equalized at $6.187 \mathrm{th}$ t-shirt when taking into account the cover stitch processes conducted with the two different systems (Figure 5). For each t-shirt produced over this number, the total expenses of the non-automatic system will exceed the total expenses of the automatic system.

Due to the enough experience of the operator using these two systems, there was no diminution in the dimension of the $\mathrm{t}$-shirts after the cover stitch process.

The smaller size of the cylindrical part to be sewn has increased the time, as it makes holding and turning inconvenient. While the circumference of hemline is $90 \mathrm{~cm}$, the two sleeves hem circumference are 72 $\mathrm{cm}$ in total, as the right and the left arm. However, average sewing time of sleeve hem was calculated higher compared to hemline. This indicates that cover stitch involves challenging processes for smaller parts. In addition, this also indicates that it is not possible to reach maximum speeds during the sewing of small parts, especially in the cover stitch processes. Standard time differences between the two systems are interpreted in the cost analysis of the systems.

Since direct drive motors are used at both systems (meaning that equal energy consumption is achieved in both systems) and the machine processing times of the two systems do not make a significance difference (the reparation process is carried out by the operator in the non-automatic system), the energy costs are not included in the financial calculations. The main reason why the measured standard times 
per both operations became different was the subsequent reparation process.

Even though the automatic system might be advantageous in terms of investment, it has some disadvantageous aspects, as well. These aspects are as follows:

- As the amount of folding at the edges of the t-shirts where the cover stitch will be processed is not predetermined, the operators can cause the t-shirt to fold excessively, this may result in shortening more than that required on the t-shirt edges (hemline or sleeve hem). In order to avoid this problem, operators should be trained and gain skills about folding processes. Besides, the automatic system should be supported with a guide, photocell or sensors to prevent the risk of excess folding and to minimize the quality problems related to body dimensions by completing the process with minimum reparation.

- Depending on the fabric construction and the raw material (e.g. jersey), unwanted conditions during production such as folding and stretching may occur. Therefore, even if the product is sewn with the automatic system, the possibility of re-reparation may take place even if the probability is very low.

All these calculations had been carried out for the twin needle cover stitch process belonging to a t-shirt production. In the system preference studies for producing a different product, all the calculations mentioned above need to be repeated starting from the beginning.

The utilization of the 4-point system in evaluating the process quality in this study is thought to lead to the use of the system in new areas.

\section{References}

Ala, D. M. and İkiz, Y., (2015), "Defect Detection of Velvet Bathrobe Fabrics and Grading with Demerit Point Systems”, Pamukkale Univ Muh Bilim Derg, Vol. 21 (7): 288-295.

Baykal, P. D. and Tunç, M., (2011), “An Investigation on Bathrobe Manufacturing Management”, Çukurova University Journal of the Faculty of Engineering and Architecture, 26(2): 9-17.

Güner M., (2010), “Tekstil ve Konfeksiyonda İş Etüdü”, Ege Üniversitesi Basım Evi, İzmir, Turkey.

Güner, M., (2018), “Konfeksiyon İşletmelerinde Organizasyon ve Planlama”, Ege Üniversitesi Basım Evi, İzmir, Turkey.

Gürarda, A., (2015), "Konfeksiyon İşlemleri ile Kumaş Özellikleri Arasındaki İlişkinin İncelenmesi, Tekstil ve Mühendis, 22 (99): 41-50.

Kurumer G., (2007), “Konfeksiyon Üretimi ve Teknolojisi”, Printer Ofset Matbaacılık, İzmir, Turkey.

Kurumer, G., and Bozkurt B., (1992), "Reçme Dikişi ve İplikli Overlok Dikişi Türlerine Ait Standart Dikim Sürelerinin Belirlenmesi”, Tekstil ve Konfeksiyon, 2 (1): 56-61. 